\title{
Natural products that inhibit carbonic anhydrase
}

\author{
Sally-Ann Poulsen and Rohan A. Davis
}

Eskitis Institute for Cell and Molecular Therapies, Griffith University, Brisbane, Queensland 4111, Australia.

S.A.-P. E-mail: s.poulsen@griffith.edu.au, Tel.: +61 737357825

R.A.D. E-mail: r.davis@griffith.edu.au, Tel.: +61737356043

Keywords: carbonic anhydrase, natural products, coumarin, phenol, polyamine, sulfonamide, sulfamate 


\section{Abstract}

The chemical diversity, binding specificity and propensity to interact with biological targets has inspired many researchers to utilize natural products as molecular probes. Almost all reported carbonic anhydrase inhibitors comprise a zinc binding group in their structure of which the primary sulfonamide moiety $\left(-\mathrm{SO}_{2} \mathrm{NH}_{2}\right)$ is the foremost example and to a lesser extent the primary sulfamate $\left(-\mathrm{O}-\mathrm{SO}_{2} \mathrm{NH}_{2}\right)$ and sulfamide $\left(-\mathrm{NH}-\mathrm{SO}_{2} \mathrm{NH}_{2}\right)$ groups. Natural products that comprise these zinc binding groups in their structure are however rare and relatively few natural products have been explored as a source for novel carbonic anhydrase inhibitors. This chapter will highlight the recent and growing interest in carbonic anhydrase inhibitors sourced from nature, demonstrating that natural product chemical space presents a rich source of potential alternate chemotypes for the discovery of novel drug-like carbonic anhydrase inhibitors.

\section{Introduction}

Carbonic anhydrases (CAs) are zinc metalloenzymes that catalyze the reversible hydration of carbon dioxide to bicarbonate and a proton (1). The active site zinc cation is the implied target for small molecule inhibitors to block the endogenous CA catalyzed reaction. Almost all reported CA inhibitors comprise a zinc binding group (ZBG) of which the primary sulfonamide moiety ($\left.\mathrm{SO}_{2} \mathrm{NH}_{2}\right)$ is the foremost example, and to a lesser extent the primary sulfamate $\left(-\mathrm{O}-\mathrm{SO}_{2} \mathrm{NH}_{2}\right)$ and primary sulfamide $\left(-\mathrm{NH}-\mathrm{SO}_{2} \mathrm{NH}_{2}\right)$ groups. Compounds sourced from nature that comprise either a primary sulfonamide, sulfamate or sulfamide moiety in their structure are exceedingly rare. A literature search of the Dictionary of Natural Products (DNP) database (2) (a comprehensive and fully-edited database on natural products (NPs)) revealed just two NP primary sulfonamide compounds, (-)-altemicidin 1 and psammaplin C 2, and five NP primary sulfamate compounds, nucleocidin 3,(3) 5'-O-sulfamoyl adenosine 4,(4) 5'-O-sulfamoyl 2chloroadenosine 5,(5) 5'-O-sulfamoyl 2-bromoadenosine $6(5,6)$ and 5'-O-sulfamoyl tubercidin 7 (Figure 1) (7, 8). (-)-Altemicidin 1 is a marine alkaloid isolated from the actinomycete strain Streptomyces sioyaensis (9). This compound exhibited potent acaricidal activity as well as strong inhibition of tumor cell growth (10). A total synthesis of $\mathbf{1}$ as well as the isolation of two secondary sulfonamide analogues of 1 have subsequently been reported (9). Psammaplin C 2 is a bromotyrosine amino acid derivative isolated from the marine sponge Pseudoceratina purpurea; $(11,12)$ no bioactivity for this alkaloid has been reported to date. The sulfamate nucleosides 3-7 were isolated from actinomycete species belonging to the genus Streptomyces. These structurally related sulfamates are reported to have a range of biological effects including cytotoxicity,(4) herbicidal activity, $(6-8,13)$ inhibition of blood platelet aggregation,(5) antibacterial 
activity $(5,14)$ and antitrypanosomal activity (14). Nucleocidin 3 , isolated from the fermentation broth of Streptomyces calcus, is of particular note since it was the first NP to contain either a fluorinated carbohydrate or a primary sulfamate group. This molecule became an attractive synthetic target owing to its novel structural features, with the first total synthesis reported in 1976 (15). Whilst NP 3 has been shown to exhibit broad spectrum antibacterial effects as well as potent antitrypanosomal activity, its potential use in the clinic has been limited due to toxicity (16). The NPs 1-7 have not been investigated for CA inhibition properties, however it is likely that these compounds would inhibit CA activity owing to the presence of an unhindered primary sulfonamide or primary sulfamate moiety within their structure. Finally, our search of the DNP failed to identify any NP primary sulfamides.

Figure 1. Natural products (NPs) that comprise a primary sulfonamide or sulfamate moiety in their structure. A.) NP primary sulfonamides: (-) altemicidin 1 and psammaplin C 2. B.) NP primary sulfamates: nucleocidin 3, 5'-O-sulfamoyl adenosine 4, 5'-O-sulfamoyl 2chloroadenosine 5, 5'-O-sulfamoyl 2-bromoadenosine 6 and 5'-O-sulfamoyl tubercidin 7.

A

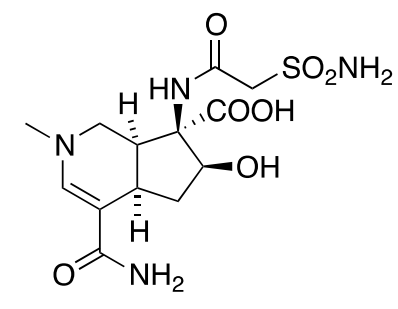

1<smiles>NS(=O)(=O)CCNC(=O)/C(Cc1ccc(O)c(Br)c1)=N\O</smiles>

2
B<smiles>Nc1ncnc2c1ncn2[C@@H]1O[C@](F)(COS(N)(=O)=O)[C@@H](O)[C@H](O)[C@@H]1O</smiles>

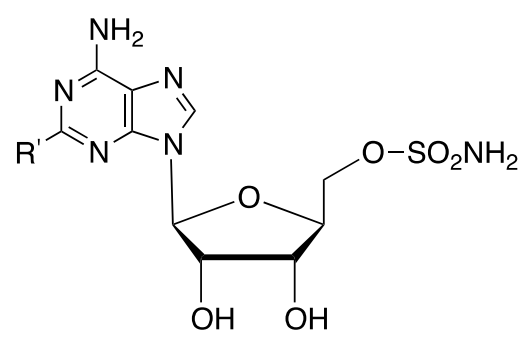

$4 \mathrm{R}^{\prime}=\mathrm{H}$ $5 \mathrm{R}^{\prime}=\mathrm{Cl}$ $6 \mathrm{R}^{\prime}=\mathrm{Br}$<smiles>Nc1ncnc2c1ccn2[C@@H]1O[C@H](COS(N)(=O)=O)[C@@H](O)[C@H]1O</smiles>

7

At the time of writing the Protein Data Bank (PDB) contained X-ray structures of $\sim 160$ sulfonamide ligands $\left(\mathrm{R}-\mathrm{SO}_{2} \mathrm{NH}_{2}\right)$ in complex with hCA II ( $\mathrm{h}=$ human). The binding mode of the 
sulfonamide anion $\left(\mathrm{R}-\mathrm{SO}_{2} \mathrm{NH}^{-}\right)$to the $\mathrm{Zn}^{2+}$ cation is invariant in these structures, with the sulfonamide anion coordinated to the active site $\mathrm{Zn}^{2+}$. Primary sulfamates and sulfamides, ZBG isosteres of primary sulfonamides, contribute an additional $\sim 35$ X-ray structures of ligands in complex with hCA II in the PDB. Of the remaining PDB protein-ligand structures most comprise very simple ligands such as anions or small organic molecules, there are however several structures comprising more complex alternate CA ligands, some of which are NPs.

NPs comprise a vast collection of diverse chemical structures and have proven to be an invaluable source of new chemotherapies (17-22). Plant NPs have been the basis of traditional medicine for thousands of years and continue to actively contribute to contemporary drug discovery (22). In more recent times, marine macro- and micro-organisms along with terrestrial microbes have been the source of numerous lead molecules or drugs (23). The significance of NPs in drug discovery is most evident in the anticancer and anti-infective therapeutic areas (2427). For example, between 1940 and 2011 48.6\% of all new anticancer small molecule therapies approved by the FDA were either NPs or NP derivatives (27). Furthermore between 1981 and $201175 \%$ of all antibacterial new chemical entities were either NPs or their derivatives (27). The success of NPs and their semi-synthetic derivatives as therapeutic agents is intrinsically linked to the fact that NPs have been biologically pre-validated and selected during evolution to bind to biosynthetic enzymes (28-33). It has been hypothesized that this inherent capacity to bind in biological space allows NPs to also recognize human therapeutic targets $(28,30,33)$. Furthermore, computational studies have shown that NPs occupy complementary areas of chemical space compared with synthetic compounds, and thus should be implemented to increase the chemical complexity and drug-likeness of screening libraries (29-32). The chemical diversity, binding specificity and efficiency, and propensity to interact with biological targets have inspired many researchers to utilize NPs as molecular probes. These studies go beyond the identification of potential new lead or drug molecules, and have increased our understanding of biological pathways and systems $(34,35)$. While the primary sulfonamide and sulfamate moieties are poorly represented in NP chemical space, this space does provide a rich source of alternate chemotypes for the discovery of CA inhibitors with a different enzyme binding mode to the typical ZBGs. The remainder of this chapter will highlight the recent and growing interest in novel CA inhibitors sourced from nature.

\section{Natural products that inhibit carbonic anhydrase}

Several classes of novel CA inhibitors have been identified from screening collections of NPs, 
most notable are coumarin and phenol containing NPs (36). NPs comprising these fragments display diverse profiles of CA inhibition when compared to classical ZBGs and these will be discussed further in the following sections. In addition a selection of NP-derived CA inhibitors have been synthesized where the NP scaffold has been synthetically modified to incorporate the classical ZBG of CA inhibitors i.e. sulfonamide, sulfamate or sulfamide. A summary of these hybrid molecules will also be presented.

\section{Coumarins}

Coumarin compounds are abundant secondary metabolites in plants and are found to a lesser extent in microorganisms and animal sources. Plant coumarins are phytoalexins, defense compounds produced when the plant is under threat from other organisms, and have attracted interest owing to a range of biological activities including antimicrobial, molluscicidal, acaricidal, antiviral, anticancer, antioxidant and anti-inflammatory properties (37). The coumarin structure comprises a benzopyrone core, with NP coumarins categorized as a) simple coumarins, b) furanocoumarins, c) pyranocoumarins, d) bis- and triscoumarins; or e) coumarinolignans (37). Simple coumarins, including coumarin 8 (Figure 2) are highly abundant in several plant species belonging to the taxonomic families Umbelliferae, Rutaceae and Compositae (37). A recent review of coumarin-based drugs highlights the growing interest in the coumarin compound class to deliver new therapeutics,(38) with potential therapeutic applications driving efforts towards the isolation and the structural characterization of further novel bioactive coumarin derivatives. In recent years it was discovered that NP coumarins inhibit CA enzymes via an alternate and unprecedented mechanism to classical sulfonamides,(39) these findings are described next.

Nature Bank is a unique drug discovery resource that encompasses a diverse collection of $>50,000$ biota samples of plants, fungi and marine invertebrates collected from Australia, China and Papua New Guinea along with biota extracts, semi-purified fractions and pure compounds (40). A selection of Leionema ellipticum (family Rutaceae) extracts was sourced from Nature Bank and screened using Fourier transform ion cyclotron resonance electrospray ionization mass spectrometry (FTICR ESI MS) for binding to bovine CA II (bCA II) (39). From this study the NP coumarin, 6-(1S-hydroxy-3-methylbutyl)-7-methoxy-2H-chromen-2-one 9 was identified as a ligand for bCA II as it formed a noncovalent complex that could be detected by ESI MS. In follow on studies it was demonstrated that coumarin 9 inhibits a spectrum of human CAs in an unprecedented time dependent manner.(41) The usual enzyme assay conditions to investigate small molecule inhibition of CA activity is to incubate the test compound with the CA protein of 
interest for 15 minutes prior to monitoring the effect on $\mathrm{CA}$-mediated $\mathrm{CO}_{2}$ hydration. Under these conditions this coumarin had only weak CA inhibition prompting us to extend the pre-incubation time. Following 6 hours of pre-incubation with hCA II the $K_{\mathrm{i}}$ of coumarin 9 dropped to $60 \mathrm{nM}$ (with a similar reduction in $K_{\mathrm{i}}$ at other CA isozymes also observed). As the coumarin chemotype lacked a classic ZBG typical of known small molecule CA inhibitors and displayed unusual timedependent inhibition it was important to understand how this chemotype binds to and inhibits CAs. Using protein X-ray crystallography the crystal structure of hCA II with this NP was obtained at a resolution of $2.0 \AA$ (Figure 3). The coumarin 9 was not observed, instead the hydrolysis product of $\mathbf{9}$, the cinnamic acid derivative $\mathbf{1 0}$ was identified (41). Esterase activity is known for CAs (42-44) and the observation of cinnamic acid 10 rather than NP coumarin $\mathbf{9}$, although unexpected, could be rationalized as a consequence of hCA II esterase activity leading to hydrolysis of the lactone of $\mathbf{9}$. The bulky hydrolysis product $\mathbf{1 0}$ then plugged the CA active site cavity entrance, exhibiting no interactions with the catalytic zinc ion. This unusual inhibition mode is previously unobserved for CAs and together with the coumarin pedigree in medicinal chemistry is suggestive of a potential new avenue for drug development compared to the ZBGs of classical CA inhibitors. Reactive Michael acceptors are a general structural alert in drug discovery, however it has been demonstrated that simple coumarins exhibit poor protein binding characteristics compared to other carbonyl containing Michael acceptors $(45,46)$. The lower reactivity of the coumarin double bond compared with other Michael acceptors, has been attributed to it being part of a pseudoaromatic system (47).

Figure 2. NP coumarin CA inhibitors. A.) Coumarin 8. B.) CA hydrolysis of coumarin 9 to form the cinnamic acid compound $\mathbf{1 0 .}$

A

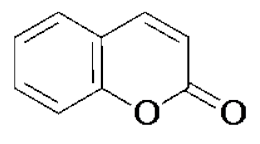

8

B

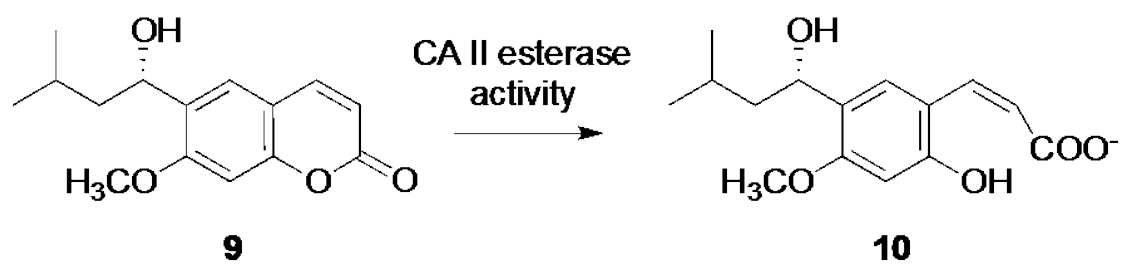


Figure 3. Detailed interactions between hCA II and NP coumarin 9 hydrolysis product 10 from a protein X-ray crystal structure. The catalytic site showing the tetrahedral $\mathrm{Zn}^{2+}$ cation (violet sphere) with the three coordinated His ligands (His94, His96, and His119) and a water molecule (red sphere). The cinnamic acid 10 (gold) interacts with three active site ordered water molecules (red spheres), with Phe131 and Asn67 (CPK colors) from the active site as well as with Glu238sym (yellow) from a symmetry related enzyme molecule. The proton shuttle residue His64 is shown (CPK colors). Reprinted with permission from Maresca, A.; Temperini, C.; Vu, H.; Pham, N. B.; Poulsen, S.-A.; Scozzafava, A.; Quinn, R. J.; Supuran, C. T. J. Am. Chem. Soc. 2009, 131, 3057. Copyright 2009 American Chemical Society.

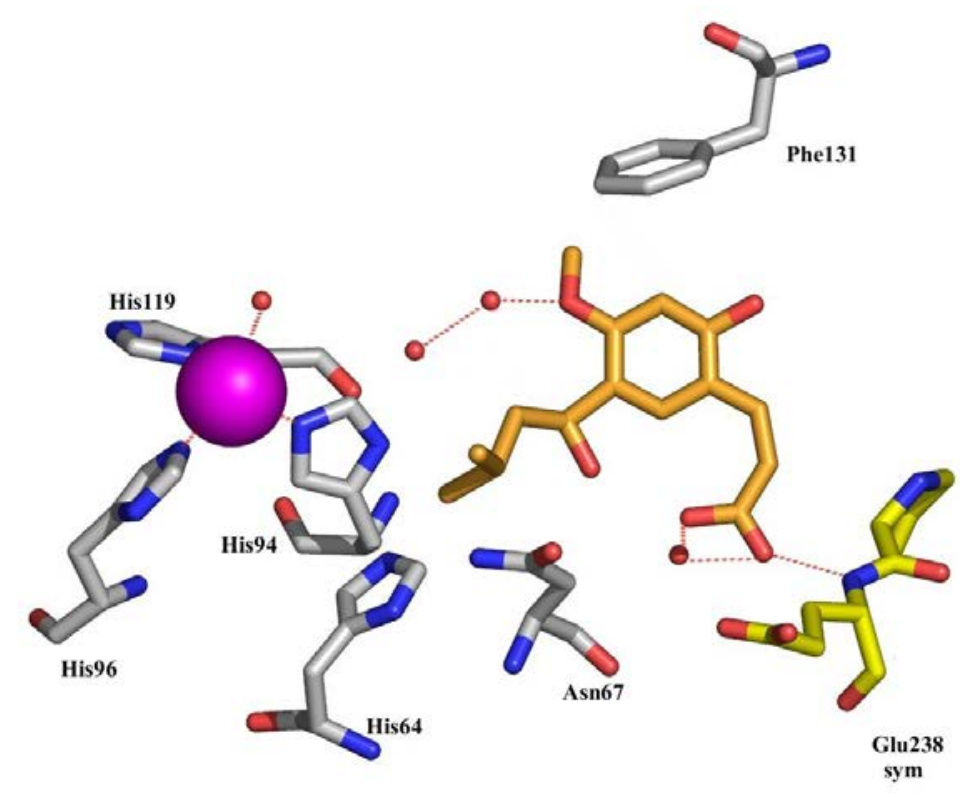

Following the findings outlined above we performed a substructure search of the Nature Bank (40) pure compound repository against the bare coumarin scaffold $\mathbf{8}$. A set of 81 coumarins were identified and from this a subset of 27 coumarins were sourced in sufficient quantity and purity for follow up evaluation as CA inhibitors (48). These NP coumarins, compounds 11-37 (Figure 4) comprise 24 plant coumarins (compounds 11-34) and three marine coumarins (compounds 35-37). Specifically, the plant NPs comprise avicennin 11,(49,50) trans-avicennol $\mathbf{1 2 , ( 5 1 , 5 2 )}$ calanolide B 13,(40,53) dihydrogeiparvarin 14,(54) geiparvarin 15,(54, 55) dehydromarmin 16,(54) xanthyletin 17,(56) xanthoxyletin 18,(51,56) ceylantin 19,(57) alloxanthoxyletin 20,(56) fraxidin 21,(58) fraxin 22,(59) scopoletin 23,(60) 6,7,8-trimethoxycoumarin 24,(61) 5,7,8trimethoxycoumarin 25,(61) 7-hydroxy-8-methoxycoumarin $\mathbf{2 6 , ( 6 0 )}$ isoscopoletin 27,(62) 
fraxoside 28,(63) scopolin 29,(64) murralongin 30,(65) (+)-isomurralonginol nicotinate 31,(66) isophellodenol C 32,(67) ellagic acid 33 (68) and nasutin B 34 (69). The ascidian NP coumarins include lamellarins E 35,(70) B 36,(71) and G 8-sulfate 37 (72). A variety of bioactivities have been reported for these coumarins, for example calanolide B 13 isolated from the tropical rainforest tree Calophyllum lanigerum, displayed protection against HIV-1 replication and cytopathicity $\left(E_{50}=0.4 \mu \mathrm{M}\right) .(53)$ Dihydrogeiparvarin 14 and geiparvarin 15, both isolated from Geijera parviflora, $(54,55)$ possessed significant in vitro activity against human carcinoma of the nasopharynx.(73, 74) Xanthoxyletin 18,(51,56) purified from a variety of Citrus species, acts as a DNA-damaging agent,(75) while several synthetic derivatives have been shown to exhibit toxicity towards L-1210 leukemia cells with $I_{50}$ values ranging from 0.9 to $60.3 \mu \mathrm{M}(75)$. The inhibition activity data for the NP coumarins 9 and 11-37 against hCA I and II (off-target isozymes), as well hCA IX and XII (isozymes of interest in cancer drug development) is presented in Table 1. Data for the simplest coumarin 8 and standard CA inhibitors (Figure 5) is included for development of structure-activity relationships (SAR).

Figure 4. NP coumarin library (11-37) sourced from Nature Bank $(40,48)$. 


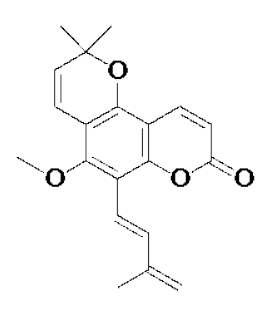

11

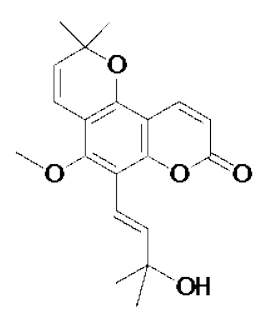

12

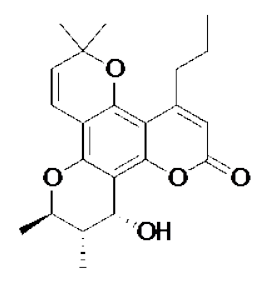

13
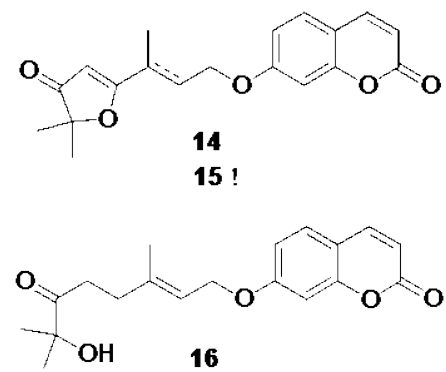

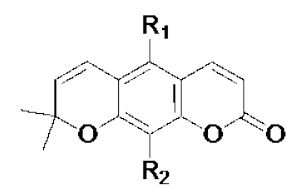

$17 \mathrm{R}_{1}=\mathrm{H}$

$18 \mathrm{R}_{1}=\mathrm{OCH}_{3} \quad \mathrm{R}_{2}=\mathrm{H}$

$19 \mathrm{R}_{1}=\mathrm{OCH}_{3} \quad \mathrm{R}_{2}=\mathrm{OCH}_{3}$

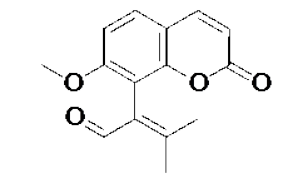

30<smiles>C/C(=C\Cc1cc2ccc(=O)oc2cc1O)CO</smiles>

32<smiles>[R20]Oc1cc2c(=O)oc3c(O[R20])c(O[R20])cc4c(=O)oc(c1O)c2c34</smiles>

$33 \mathrm{R}_{1}=\mathrm{H} \quad \mathrm{R}_{2}=\mathrm{H} \quad \mathrm{R}_{3}=\mathrm{H}$

$34 \mathrm{R}_{1}=\mathrm{CH}_{3} \quad \mathrm{R}_{2}=\mathrm{CH}_{3} \quad \mathrm{R}_{3}=\mathrm{CH}_{3}$

31

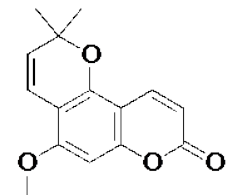

20

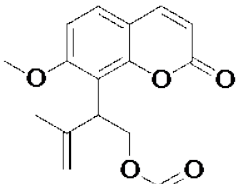

N

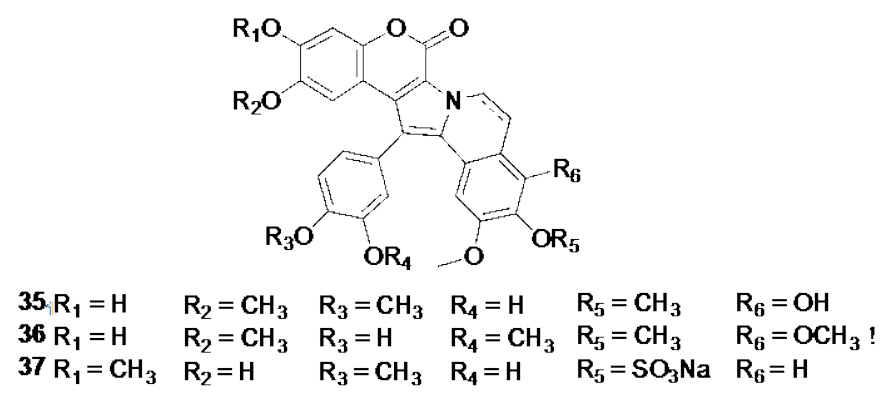

$$
\begin{array}{llll}
\mathbf{2 1} \mathrm{R}_{1}=\mathrm{OH} & \mathrm{R}_{2}=\mathrm{OCH} \mathrm{H}_{3} & \mathrm{R}_{3}=\mathrm{OCH}_{3} & \mathrm{R}_{4}=\mathrm{H} \\
\mathbf{2 2} \mathrm{R}_{1}=\mathrm{OH} & \mathrm{R}_{2}=\mathrm{OH} & \mathrm{R}_{3}=\mathrm{OCH}_{3} & \mathrm{R}_{4}=\mathrm{H} \\
\mathbf{2 3} \mathrm{R}_{1}=\mathrm{H} & \mathrm{R}_{2}=\mathrm{OH} & \mathrm{R}_{3}=\mathrm{OCH}_{3} & \mathrm{R}_{4}=\mathrm{H} \\
\mathbf{2 4} \mathrm{R}_{1}=\mathrm{OCH}_{3} & \mathrm{R}_{2}=\mathrm{OCH}_{3} & \mathrm{R}_{3}=\mathrm{OCH}_{3} & \mathrm{R}_{4}=\mathrm{H} \\
\mathbf{2 5} \mathrm{R}_{1}=\mathrm{OCH}_{3} & \mathrm{R}_{2}=\mathrm{OCH}_{3} & \mathrm{R}_{3}=\mathrm{H} & \mathrm{R}_{4}=\mathrm{OCH}_{3} \\
\mathbf{2 6} \mathrm{R}_{1}=\mathrm{OCH}_{3} & \mathrm{R}_{2}=\mathrm{OH} & \mathrm{R}_{3}=\mathrm{H} & \mathrm{R}_{4}=\mathrm{H} \\
\mathbf{2 7} \mathrm{R}_{1}=\mathrm{H} & \mathrm{R}_{2}=\mathrm{OCH} & \mathrm{R}_{3}=\mathrm{OH} & \mathrm{R}_{4}=\mathrm{H} \\
\mathbf{2 8} \mathrm{R}_{1}=\mathrm{O}^{n}-\mathrm{D}-\mathrm{Glc} c & \mathrm{R}_{2}=\mathrm{OH} & \mathrm{R}_{3}=\mathrm{OCH}_{3} & \mathrm{R}_{4}=\mathrm{H} \\
\mathbf{2 9} \mathrm{R}_{1}=\mathrm{H} & \mathrm{R}_{2}=\mathrm{O}^{n}-\mathrm{D}-\mathrm{Glc}_{3} \mathrm{R}_{3}=\mathrm{OCH}_{3} & \mathrm{R}_{4}=\mathrm{H}
\end{array}
$$<smiles>[R]c1c([R])c([R])c2oc(=O)ccc2c1[R]</smiles>

Figure 5. Standard CA inhibitors: acetazolamide AZA, zonisamide ZNS and topiramate TPM.<smiles>CC(=O)Nc1nnc(S(N)(=O)=O)s1</smiles>

AZA<smiles>NS(=O)(=O)Cc1noc2ccccc12</smiles>

ZNS<smiles>CC1(C)O[C@H]2CO[C@]3(COS(N)(=O)=O)OC(C)(C)O[C@@H]3[C@H]2O1</smiles>

TPM 
Table 1. Inhibition data for coumarins 8, 9, 11-37 against hCA isozymes I, II, IX and XII.(48) Standard inhibitors (AZA, ZNS and TPM) are included for comparison (76-78).

\begin{tabular}{|c|c|c|c|c|}
\hline \multirow[t]{2}{*}{ Compd } & \multicolumn{4}{|c|}{$K_{\mathrm{i}}(\mu \mathrm{M})^{\mathrm{a}-c}$} \\
\hline & CA I & CA II & CA IX & CA XII \\
\hline 8 & 3.10 & 9.20 & $>1000$ & $>1000$ \\
\hline 9 & 0.08 & 0.06 & 54.5 & 48.6 \\
\hline 11 & 7.66 & $>100$ & 0.62 & 0.79 \\
\hline 12 & 8.46 & $>100$ & 0.78 & 0.77 \\
\hline 13 & 9.31 & 50.7 & 0.83 & 0.81 \\
\hline 14 & 59.2 & 63.4 & 0.89 & 0.60 \\
\hline 15 & 9.75 & $>100$ & 0.60 & 0.83 \\
\hline 16 & 7.81 & $>100$ & 4.03 & 0.70 \\
\hline 17 & 21.5 & $>100$ & 7.51 & 25.7 \\
\hline 18 & 7.71 & $>100$ & 0.74 & 0.96 \\
\hline 19 & 9.21 & 49.3 & 0.86 & 8.35 \\
\hline 20 & 5.60 & $>100$ & 3.50 & 9.10 \\
\hline 21 & 9.89 & $>100$ & 0.85 & 7.84 \\
\hline 22 & 4.86 & 94.3 & 0.61 & 7.70 \\
\hline 23 & 10.56 & $>100$ & 0.96 & 4.05 \\
\hline 24 & 0.0097 & $>100$ & 6.58 & 18.2 \\
\hline 25 & 4.31 & 9.65 & 0.76 & 0.83 \\
\hline 26 & 36.4 & $>100$ & 0.85 & 9.12 \\
\hline 27 & 14.0 & $>100$ & 7.37 & 4.14 \\
\hline 28 & 5.04 & $>100$ & 0.37 & 7.45 \\
\hline 29 & 5.93 & $>100$ & 8.72 & 0.78 \\
\hline 30 & 9.11 & $>100$ & 8.12 & 7.44 \\
\hline
\end{tabular}




$\begin{array}{lllll}31 & 5.84 & >100 & 0.67 & 7.39 \\ 32 & 7.52 & 78.9 & 9.75 & 0.77 \\ 33 & 68.2 & >100 & 79.8 & 8.15 \\ \mathbf{3 4} & 44.1 & >100 & 17.4 & 7.42 \\ \mathbf{3 5} & 6.45 & >100 & 3.22 & 9.07 \\ \mathbf{3 6} & 40.1 & >100 & 6.33 & 8.51 \\ \mathbf{3 7} & 6.55 & >100 & 3.27 & 1.79 \\ \text { AZA } & 0.25 & 0.012 & 0.025 & 0.0057 \\ \text { ZNS } & 0.056 & 0.035 & 0.005 & 11 \\ \text { TPM } & 0.25 & 0.005 & 0.058 & 0.0038\end{array}$

${ }^{a}$ This inhibition data was acquired following a $6 \mathrm{~h}$ incubation time with enzyme using a stopped flow assay that monitors the CA catalyzed hydration of $\mathrm{CO}_{2}$ (79). ${ }^{b}$ Errors in the range of $\square 5 \%$ of the reported value, from three determinations. ${ }^{c}$ All proteins were recombinant.

Since the discovery of the NP coumarin 9 synthetic libraries of coumarins and thiocoumarins have been prepared and evaluated as CA inhibitors (80-82). The complexity and diversity of NP coumarin structures far exceeds that described for synthetic coumarin CA inhibitors. Coumarin 8, the simplest coumarin, is not an appreciable inhibitor of CA IX or XII however it is a weak inhibitor of off-target CA I and CA II, with $K_{\mathrm{i}}$ of 3.1 and $9.2 \mu \mathrm{M}$, respectively. The NP coumarins are substituted at any of six available sites, with many fused to form tricyclic, tetracyclic or larger ring systems. This diversity does not readily allow simple SAR to be defined, however several trends surrounding CA inhibition are evident. Most obvious is that the NP coumarin library members are very weak CA II inhibitors, most have $K_{i} S>100 \mu \mathrm{M}$, the only exception being the trimethoxycoumarin $25\left(K_{\mathrm{i}}=9.65 \mu \mathrm{M}\right)$. When compared to the structurally related methoxy/hydroxy coumarins 21-24, 26 and 27, compound 25 differs only in the pattern of substituents, this SAR indicates that it may be a combination of interacting substituents that directs the CA inhibition profile at CA II. At CA I, IX and XII many of the NP coumarins have $K_{\mathrm{i}} \mathrm{S}$ in the range of $1-10 \mu \mathrm{M}$, this tight grouping of $K_{\mathrm{i}} \mathrm{S}$ reflects minimal isozyme selectivity with these coumarins, however there are a few outliers to this general trend and these compounds represent interesting structures owing to their CA isozyme selectivity characteristics. At CA I there was one stand out compound being compound 24, a nanomolar CA I inhibitor. This 
trimethoxy coumarin is the most potent of any of the NP coumarins at CA I and is a structural isomer of 25, the only potent CA II coumarin of the study. Around half of the NP coumarins have submicromolar inhibition of the isozymes CA IX and XII, some of these coumarins $(\mathbf{1 1}, \mathbf{1 2}, \mathbf{1 3}$, 14, 15, 18 and 25) are submicromolar at both CA IX and XII, while the remainder are submicromolar at either CA IX (19, 21-23, 26, 28 and 31) or CA XII (16, 29 and 32). This subset of NP coumarins has viable selectivity characteristics that warrant further studies in cell-based models of CA in cancer.

\section{Phenols}

The first single crystal X-ray structure of phenol $\mathbf{3 8}$ and a CA protein (hCA II) was reported in 1994 and identified that $\mathbf{3 8}$ binds in an unprecedented way within the enzyme active site.(83) It was shown that the phenolic $\mathrm{OH}$ interacts with the zinc-bound water molecule/hydroxide ion through a hydrogen bond while a second hydrogen bond formed between the phenolic $\mathrm{OH}$ and the $\mathrm{NH}$ amide of Thr199, an amino acid critical for the catalysis and inhibition of various CAs. NPs containing the phenol fragment $\mathbf{3 8}$ are highly abundant in nature. A substructure search of the DNP (2) against the phenol fragment identified $>50,000$ NPs from the 246,994 database entries that contain this fragment ( $20 \%$ of all entries). Early CA inhibitory studies focused on simple, commercially available mono-, di- or tri-substituted phenols that are also found in nature (2) such as pyrocatechol 39, resorcinol 40, hydroquinol 41, salicylic acid 42, p-hydroxybenzoic acid 43, p-coumaric acid 44, caffeic acid 45, ferulic acid 46, gallic acid 47 and syringic acid 48 (Figure 6) $(84,85)$. A number of phenolic-NPs containing more complex scaffolds 49-57 have since been sourced from the Davis open-access compound repository housed at the Queensland Compound Library (QCL),(86) and screened against selected CAs (Figure 6) (87, 88). These phenolic-derivatives include the endophytic fungal metabolites, (-)-xylariamide $A$ 49,(89) and its synthetic enantiomer (+)-xylariamide A 50,(89) xanthones $\mathbf{5 1}$ and $\mathbf{5 2 , ( 9 0 )}$ the marine ascidian-derived alkaloids, polyandrocarpamines A 53 and B 54 (91, 92) and the plant secondary metabolites, endiandrins A 55 (93) and B 56,(94) and (-)-dihydroguaiaretic acid 57 $(93,94)$.

The phenols 38-57 have been evaluated for their inhibition of human cytosolic isoforms CA I and II (off-target) and mitochondrial isozymes CA VA and CA VB, Table 2. The latter have been recognized as potential targets for designing anti-obesity agents that act with a novel mechanism of action $(95,96)$. The simple phenolic secondary metabolites $\mathbf{3 8 - 4 8}$ have also been tested against hCA III, IV, VI, VII, IX, XII, XIII and XIV $(84,85)$. These data (not shown) indicate 
that the phenol class of NP CA inhibitor exhibits complex SAR, with small chemical changes leading to large effects on CA enzyme inhibition. The chemical diversity of phenolic NPs is vast; so far investigation of this chemotype for its interaction with CAs is in its infancy.

Figure 6. NP phenols $\mathbf{3 8 - 5 7}$ tested as CA inhibitors $(84,85,87,88)$. 


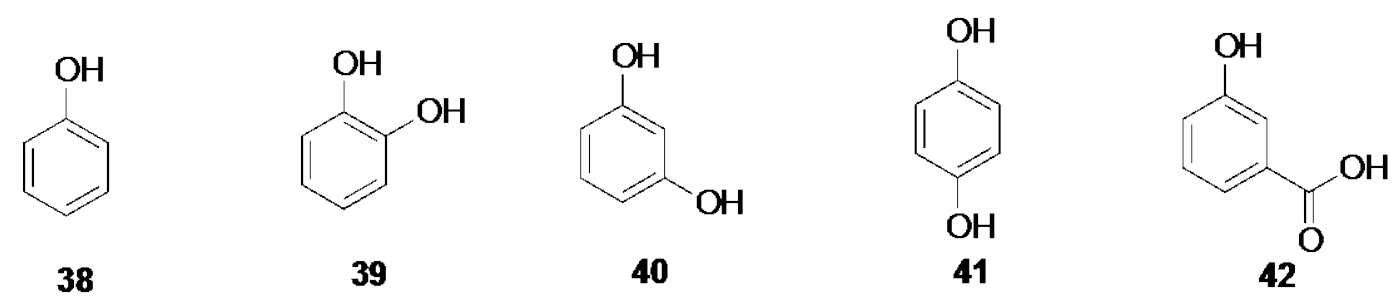<smiles>O=C(O)c1ccc(O)cc1</smiles>

43<smiles>O=C(O)c1cc(O)c(O)c(O)c1</smiles>

47<smiles>O=C(O)/C=C/c1ccc(O)cc1</smiles>

44<smiles>O=C(O)/C=C/c1ccc(O)c(O)c1</smiles>

45<smiles>COc1cc(/C=C/C(=O)O)ccc1O</smiles>

46<smiles>COc1cc(C(=O)O)cc(OC)c1O</smiles>

48<smiles>COC(=O)/C=C/C(=O)N[C](Cc1ccc(O)c(Cl)c1)C(=O)O</smiles>

49<smiles>COC(=O)/C=C/C(=O)N[C@@H](Cc1ccc(O)c(Cl)c1)C(=O)O</smiles>

50<smiles>[R]c1cc(OC)c2c(=O)c3c(C(=O)O)c(O)ccc3oc2c1</smiles>

$51 \mathrm{R}_{1}=\mathrm{Me}$

$52 \mathrm{R}_{1}=\mathrm{CH}_{2} \mathrm{OH}$<smiles>[R20]c1cc(/C=C2\N=C(N)NC2=O)ccc1O</smiles>

$53 \mathrm{R}_{1}=\mathrm{Me}$ $54 \mathrm{R}_{1}=\mathrm{H}$<smiles>COc1cc([C@H]2C(C)C(C)[C@H]2c2ccc(O)c(OC)c2)ccc1O</smiles>

55<smiles>COc1cc([C@H]2C(C)C(C)[C@H]2c2ccc(O)c(OC)c2)ccc1O</smiles>

56<smiles>COc1cc(CC(C)C(C)Cc2ccc(O)c(OC)c2)ccc1O</smiles>

57

Table 2. Inhibition data for phenolic NPs 38-57 against hCA isozymes I, II, VA and VB (84, 85, 87, 88). Standard inhibitors AZA, ZNS and TPM are included for comparison (76-78). 


\begin{tabular}{|c|c|c|c|c|}
\hline \multirow[t]{2}{*}{ Compd } & \multicolumn{4}{|c|}{$K_{\mathrm{i}}(\mu \mathrm{M})^{a, b}$} \\
\hline & CA I & CA II & CA VA & CA VB \\
\hline 38 & 10.2 & 5.5 & 218 & 543 \\
\hline 39 & 4003 & 9.9 & 55.1 & 4.2 \\
\hline 40 & 795 & 7.7 & 8.7 & 7.1 \\
\hline 41 & 10.7 & 0.090 & 14.1 & 12.5 \\
\hline 42 & 9.9 & 7.1 & 678 & 355 \\
\hline 43 & 9.8 & 10.6 & 9.2 & 10.5 \\
\hline 44 & 1.07 & 0.98 & 5.9 & 7.7 \\
\hline 45 & 2.38 & 1.61 & 6.5 & 9.1 \\
\hline 46 & 2.89 & 2.40 & 7.0 & 10.5 \\
\hline 47 & 3.20 & 2.25 & 4.1 & 9.9 \\
\hline 48 & 4.15 & 3.19 & 6.3 & 35.4 \\
\hline 49 & 239 & 8.3 & 0.095 & 0.114 \\
\hline 50 & 231 & 8.0 & 0.108 & 0.102 \\
\hline 51 & 201 & 8.4 & 0.093 & 0.103 \\
\hline 52 & 374 & 9.2 & 0.094 & 0.102 \\
\hline 53 & 10.5 & 9.6 & 0.099 & 0.070 \\
\hline 54 & 355 & 13.1 & 0.101 & 0.076 \\
\hline 55 & 368 & 11.7 & 0.093 & 0.069 \\
\hline 56 & 354 & 12.1 & 0.098 & 0.079 \\
\hline 57 & 307 & 230 & 0.085 & 0.071 \\
\hline AAZ & 0.25 & 0.012 & 0.063 & 0.054 \\
\hline TPM & 0.25 & 0.010 & 0.063 & 0.030 \\
\hline ZNS & 0.056 & 0.035 & 0.020 & 6.3 \\
\hline
\end{tabular}

${ }^{a}$ Errors in the range of $\quad$ Eeprofted vadue, from three determinations. ${ }^{b}$ All proteins were recombinant.

The $\beta$-CAs from Helicobacter pylori, Candida albicans, Candida glabrata, Cryptococcus neoformans and Brucella suis are essential for growth and have proven susceptible to inhibition with several compound classes including sulfonamides, carboxylates and boronic acids (97104). A positive correlation from enzyme assays to a cell-based anti-infective phenotype assay demonstrates that the $\beta$-CAs from these pathogens are potential druggable targets for antiinfective therapies. Mammals possess only $\alpha$-CAs, whilst many pathogenic organisms, such as 
bacteria and fungi encode $\beta$-CAs. Similarly to $\alpha$-CAs, a zinc cation defines the location of the active site of the $\beta$-CA enzymes. Phenols $\mathbf{4 9 - 5 7}(93,94)$ along with the fungal NP phenols $\mathbf{5 8 - 6 2}$ (105-107) (Figure 7) have been screened for enzyme inhibition against selected pathogen $\beta$ family CAs, Table 3. CAs from Mycobacterium tuberculosis, Candida albicans and Cryptococcus neoformans were studied and selectivity towards the pathogen isozymes over human CAs was assessed.

Figure 7. Phenolic NPs 58-62 with activity against mycobacterial and fungal CAs (87).

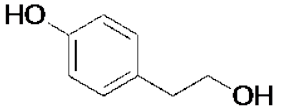

58<smiles>[R]C(=O)Cc1ccc(O)c([R])c1</smiles>

$59 \mathrm{R}^{\prime \prime}=\mathrm{H} \mathrm{R}^{\prime \prime}=\mathrm{OH}$

60 $\mathrm{R}^{\prime \prime}=\mathrm{H} \mathrm{R}^{\prime \prime}=\mathrm{NH}_{2}$

$61 \mathrm{R}^{\prime \prime}=\mathrm{Cl} \mathrm{R} \mathrm{R}^{\prime \prime}=\mathrm{OH}$

$62 \mathrm{R}^{\prime \prime}=\mathrm{Cl} \mathrm{R"}=\mathrm{NH}_{2}$

Table 3. Enzyme inhibition of pathogenic M. tuberculosis $\beta-C A$ isozymes Rv3273 and Rv1284, C. albicans isozyme Nce103, C. neoformans isozyme Can2 and human $\alpha-C A$ isozymes I and II with the NP phenols 49-62 (87) and standard CA Inhibitors AZA, ZNS, and TPM.

\begin{tabular}{lcccccc}
\hline Compd & \multicolumn{5}{c}{$K_{\mathrm{i}}(\mu \mathrm{M})^{\mathbf{a}, \boldsymbol{b}}$} \\
\cline { 2 - 7 } & CA I & CA II & Rv3273 & Rv1284 & Nce103 & Can2 \\
\hline $\mathbf{3 8}$ & 10.1 & 5.5 & 79.0 & 64.0 & 17.3 & 25.9 \\
$\mathbf{4 9}$ & 239 & 8.3 & 11.3 & 0.84 & 1.03 & 1.15 \\
$\mathbf{5 0}$ & 231 & 8.0 & 10.9 & 0.71 & 1.06 & 1.11 \\
$\mathbf{5 1}$ & 201 & 8.4 & 11.4 & 10.5 & 1.06 & 1.12 \\
$\mathbf{5 2}$ & 374 & 9.2 & 10.9 & 0.99 & 1.01 & 1.08 \\
$\mathbf{5 3}$ & 10.5 & 9.6 & 0.91 & 11.8 & 0.92 & 0.89 \\
$\mathbf{5 4}$ & 355 & 13.1 & 0.92 & 0.91 & 0.90 & 0.95 \\
$\mathbf{5 5}$ & 368 & 11.7 & 8.92 & 0.82 & 0.73 & 0.77 \\
$\mathbf{5 6}$ & 354 & 12.1 & 0.89 & 0.80 & 0.70 & 0.95 \\
$\mathbf{5 7}$ & 307 & 230 & 9.10 & 0.85 & 0.62 & 0.81 \\
$\mathbf{5 8}$ & 430 & 8.7 & 12.1 & 0.85 & 1.10 & 1.08 \\
$\mathbf{5 9}$ & 309 & 10.3 & 11.4 & 10.8 & 1.02 & 0.90 \\
$\mathbf{6 0}$ & 309 & 11.2 & 9.12 & 0.85 & 0.91 & 0.84
\end{tabular}




\begin{tabular}{ccccccc}
$\mathbf{6 1}$ & 265 & 8.6 & 10.8 & 10.3 & 1.08 & 1.12 \\
$\mathbf{6 2}$ & 237 & 131 & 11.2 & 10.5 & 1.00 & 0.85 \\
AAZ & 0.25 & 0.012 & 0.10 & 0.48 & 0.13 & 0.01 \\
TPM & 0.25 & 0.010 & 3.02 & 0.61 & 1.11 & 0.37 \\
ZNS & 0.056 & 0.035 & 0.21 & 286.8 & 0.94 & 0.97 \\
\hline
\end{tabular}

These studies showed that several phenolic NPs were selective inhibitors of mycobacterial and fungal $\beta$-CAs, with the two best performing NPs identified as (-)-dihydroguaiaretic acid $\mathbf{5 7}$ and $\mathbf{3}$ chloro-4-hydroxyphenylacetamide $\mathbf{6 2}$. Specifically, $\mathbf{5 7}$ was a sub-micromolar $\beta$-CA inhibitor with up to 495-fold selectivity over hCA I and 371-fold selectivity over hCA II. Compound $\mathbf{6 2}$ was also a low micromolar inhibitor of the fungal CAs and displayed 130- to 280-fold selectivity over the two human CAs. These compounds were the first non-sulfonamide inhibitors that display $\beta$ over $\underline{a} \square \mathrm{CA}$ enzyme selectivity. In order to determine how the phenolic-based NPs 38-62 interacted with CAs, soaking and co-crystallization studies were undertaken with the readily available protein hCA II. While the most selective NPs $\mathbf{5 7}$ and $\mathbf{6 2}$ did not yield co-crystals with CAs suitable for X-ray diffraction studies, compound $\mathbf{5 0}[(+)$-xylariamide $A]$ did at a resolution of $2 \AA$. While it was predicted that the phenolic moiety present in $\mathbf{5 0}$ would play a major role in the hCA II binding it was discovered that instead the ester carbonyl of $\mathbf{5 0}$ interacts with a zinc-bound water molecule and is further engaged in a hydrogen bond donated by the backbone amide group of Thr198 (Figure 8). In this crystal structure the electron density of the inhibitor is well defined, allowing unambiguous placement of the ligand. This was a totally new binding mode to CAs.

Figure 8. The ligand-protein interactions are illustrated schematically for hCA II in complex with compound $50[(+)$-xylariamide A]. Protein residues are shown in grey; hydrogen bond interactions are shown as dotted lines, van der Waals interactions as dashed lines. Distances are given in $\AA$. Two conformations of the phenol moiety were observed, giving rise to the appearance of the chloro substituent on both sides of the phenolic hydroxyl group; the refined occupancies for both positions are noted at each position. Reprinted with permission from Davis, R. A.; Hofmann, A.; Osman, A.; Hall, R. A.; Mühlschlegel, F. A.; Vullo, D.; Innocenti, A.; Supuran, C. T.; Poulsen, S. A. J. Med. Chem. 2011, 54, 1682. Copyright 2011 American Chemical Society. 


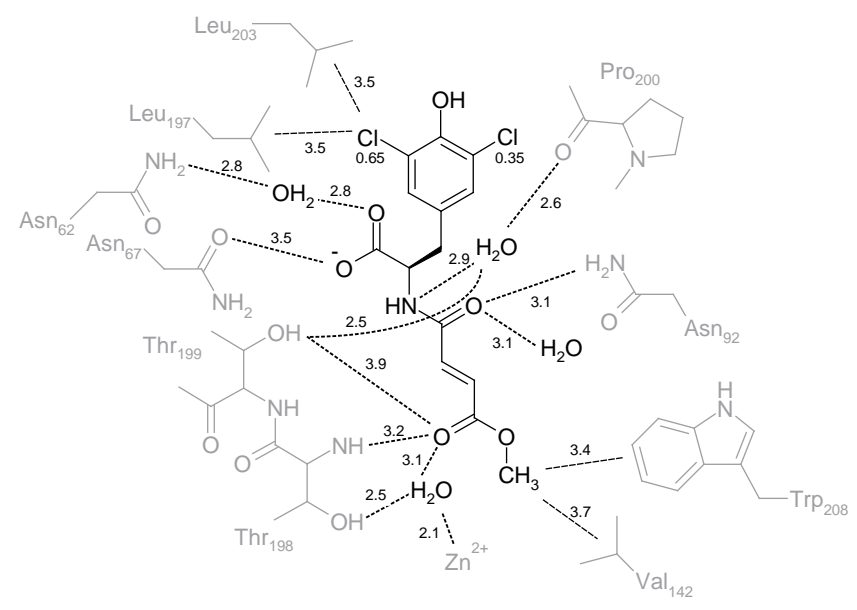

\section{Polyamines}

Polyamines belong to an alkaloid structure class and have been reported from various natural sources including terrestrial and marine animals, plants, fungi and bacteria (2). Two of the simplest polyamines isolated to date include spermine 63 and spermidine 64 (Figure 9). A substructure search of the DNP against 63 and 64 identified >400 NPs from the 246,994 database entries that comprise these alkaloid fragments (2). The polyamine chemotype has been shown to modulate multiple biological processes including gene expression, cell proliferation, translation, cell signaling, membrane stabilization and ion channel inhibition as well as antibacterial activity (108-114). Despite the myriad bioactivities reported for polyamine NPs until recently no CA inhibition had been reported. Carta et al. showed that 63, 64 and several semi-synthetic polyamine analogues inhibited hCA I-XIV with $K_{\mathrm{i}}$ values ranging from low nanomolar to millimolar (115). A single crystal X-ray structure of spermine 63 with hCA II (at a resolution of $2.0 \AA$ ) was also reported (115) showing compound 63 anchored to the zinc bound water ligand (as for phenol 38) through a network of hydrogen bonds. The terminal amine moiety of 63 is hydrogen bonded with residues Thr200 and Pro201. Notably 63 binds differently to hCA II when compared to either sulfonamides, phenols or coumarins and thus polyamines have the potential for the identification and development of additional CA inhibitors with a unique mechanism of binding and CA selectivity profile. This alkaloid structure class warrants further investigation and we expect that NPs will provide future opportunities to study additional polyamine alkaloids for CA inhibition.

Figure 9. NP polyamine CA inhibitors spermine 63 and spermidine 64 (115). 


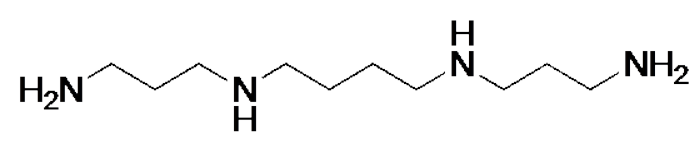

63

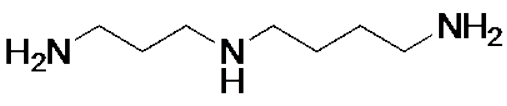

64

\section{Semi-synthetic NPs modified to incorporate a ZBG and inhibit CA}

\subsection{Carbohydrate-ZBG hybrid molecules}

Carbohydrates represent an abundant group of NPs and a selection of naturally occurring monoand disaccharides have been modified to incorporate CA recognizing ZBG's to give glycosyl primary sulfonamides (sugar- $\mathrm{SO}_{2} \mathrm{NH}_{2}$ ),(116) glycosyl primary sulfamides (sugar- $\mathrm{NH}-\mathrm{SO}_{2} \mathrm{NH}_{2}$ ) (117) and glycoconjugate sulfamates (sugar-O- $\mathrm{SO}_{2} \mathrm{NH}_{2}$ ) (118). Compounds 65-74 derived from the monosaccharides D-glucose, D-galactose, D-mannose and the disaccharide maltose are shown (Figure 10). An aromatic group, which is typical for classical CA inhibitors, is absent from these compounds and instead they comprise the hydrophilic mono- or disaccharide fragment directly attached to the ZBG. These NP-ZBG hybrid molecules have been evaluated as CA inhibitors, Table 4. All carbohydrate-ZBG hybrid compounds behaved as weak inhibitors of hCA I, with the anomeric sulfonamides 65-67 and sulfamides 68-70 also weak micromolar inhibitors of hCA II, IX and XII. In contrast the C-6 sulfamates 71-74 delivered good activity, particularly monosacchrides 71-73, which showed $K_{\mathrm{i}}<10 \mathrm{nM}$ against hCA XII. The glucose sulfamate 71 also has a $K_{\mathrm{i}}<10 \mathrm{nM}$ at hCA IX and displayed selectivity for inhibiting the tumor-associated isoforms CA IX and XII over cytosolic CA I and II. The interested reader is directed to crystal structures for anomeric sulfonamides and glycoconjugate sulfamates in complex with hCA II in the PDB (accession codes: 3HKN, 3HKQ, 3HKT, 3HKU, 3T82, 3T83, 3T84, and 3T85).

The membrane permeability properties were measured for selected carbohydrate-ZBG hybrid CA inhibitors, the results confirm that the compounds are expected to have poor passive membrane permeability. cLog $\mathrm{P}$ is an indicator of passive diffusion through cell membranes and values $<0$ are indicative of molecules with poor membrane permeability. The cLog $P$ values of the hybrid molecules 65-74 range from -2.7 for monosaccharides to -5.5 for dissacharides, Table 4. The compound design, employing a deliberate approach towards CA IX/XII isozyme selectivity by changing the physicochemical properties to impart poor membrane permeability, is consistent with these cLog P values. Membrane permeable ester 'prodrugs' of the carbohydrateZBG hybrids were also synthesized, this allows for potential oral administration, with the polar 
carbohydrate-ZBG hybrid molecules 'unmasked' in vivo enabling targeting of extracellular CA IX and XII.

Figure 10. Carbohydrate-ZBG hybrid molecules 65-74: glycosyl primary sulfonamides (sugar$\mathrm{SO}_{2} \mathrm{NH}_{2}$ ), glycosyl primary sulfamides (sugar- $\mathrm{NH}-\mathrm{SO}_{2} \mathrm{NH}_{2}$ ) and glycoconjugate sulfamates (sugar-O- $\mathrm{SO}_{2} \mathrm{NH}_{2}$ ) (116-118).

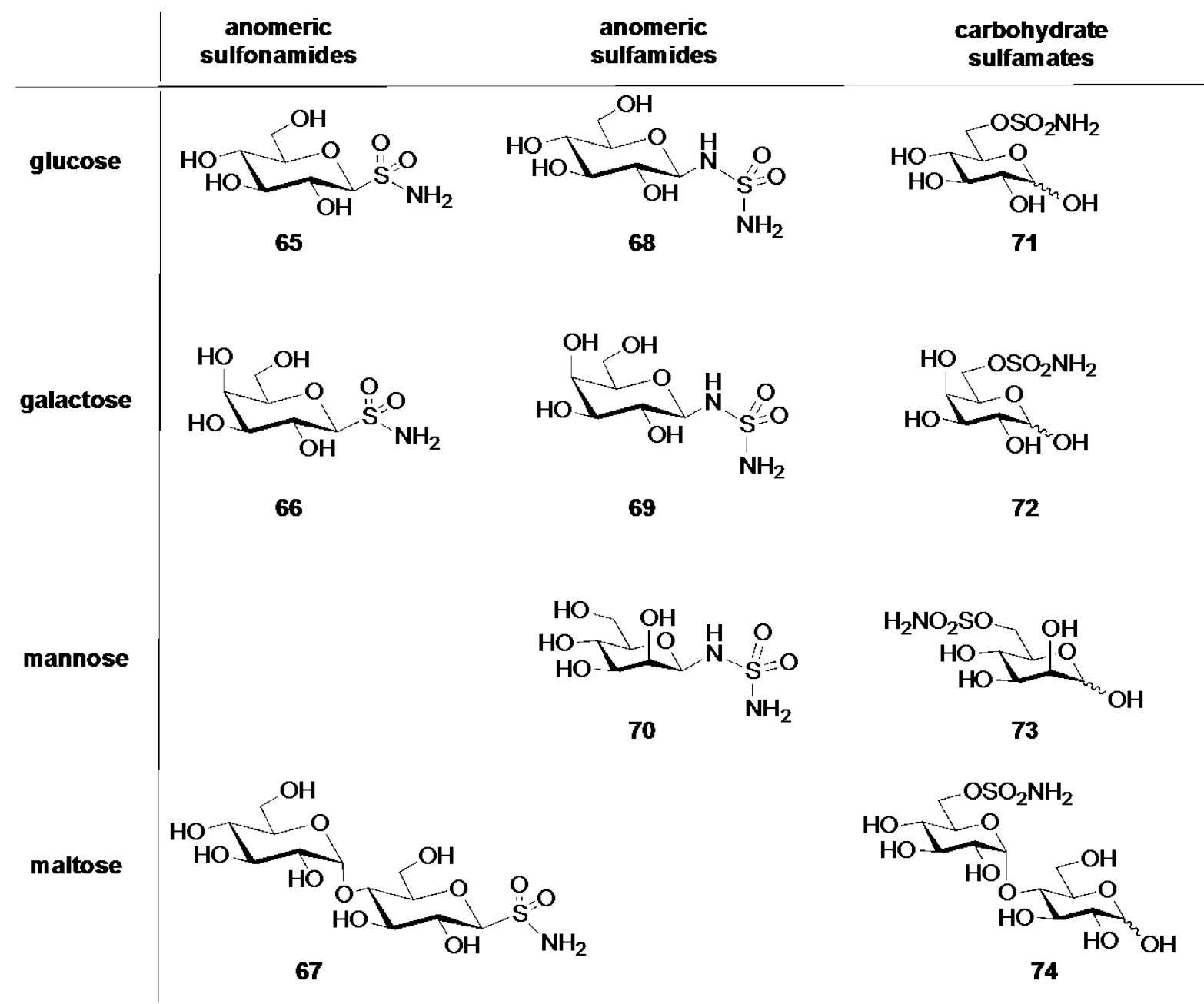

Table 4. Inhibition data of hCA Isozymes I, II, IX and XII and cLog P values for carbohydrateZBG hybrid molecules 65-74 (116-118).

\begin{tabular}{ccccc}
\hline \multirow{2}{*}{ Compd } & \multicolumn{4}{c}{$K_{\mathrm{i}}(\mathrm{nM})^{a}$} \\
\cline { 2 - 3 } CLog P $^{d}$ \\
\cline { 2 - 3 }
\end{tabular}




$\begin{array}{lccccc}65 & 3,900 & 4,910 & 4,050 & 4,690 & -2.8 \\ 66 & 3,930 & 4,550 & 4,190 & 4,800 & -2.8 \\ 67 & 4,150 & 4,100 & 4,220 & 4,840 & -5.0 \\ 68 & 75,400 & 4,680 & 6,470 & 1,970 & -2.7 \\ 69 & 65,800 & 48,500 & 940 & 8,230 & -2.7 \\ 70 & 91,900 & 21,200 & 1,790 & 5,440 & -2.7 \\ 71 & 1180 & 82 & 8.6 & 7.3 & -3.3 \\ 72 & 4500 & 93 & 62 & 7.6 & -3.3 \\ 73 & 5960 & 104 & 53 & 9.5 & -3.3 \\ 74 & 8750 & 513 & 497 & 138 & -5.5\end{array}$

${ }^{a}$ Errors in the range of $\quad 105 \%$ of the reported value, from three determinations. ${ }^{b}$ Human (cloned) isozymes. ${ }^{c}$ Catalytic domain of human (cloned) isozymes. ${ }^{d} \mathrm{CLog} \mathrm{P}$ data calculated using ChemBioDraw Ultra 11.0.

\subsection{Coumarin-ZBG and steroid-ZBG hybrid molecules}

A selection of NP-derived sulfamates are potent inhibitors of the cancer drug target steroid sulfatase (STS) and are being developed as a therapy for hormone-dependent breast cancer (119). This includes the steroidal sulfamate oestrone-3-O-sulphamate (EMATE) 75 and two coumarin based sulfamates, COUMATE-667 76 and STX-118 77 (Figure 11), which at a simpler structural level may also be considered phenolic sulfamates. These NP hybrids, modified with the sulfamate ZBG, are also potent CA inhibitors, Table 5 (120-122). It is hypothesized that dual steroid sulfatase/CA inhibitors may represent a novel method for treating hormone dependent breast cancer tumors, with the reversible binding of the sulfamates to erythrocyte CA II increasing the metabolic stability of the compounds by protecting the sulfamate moiety from rapid degradation (123). This indirect improvement of biopharmaceutical properties may persist alongside the direct effect of modulating the activity of cancer-associated CA IX and XII. The Xray crystal structure of hCA II with both 75 (124) and 76 (123) are reported. These structures conform to the classical ZBG interactions with the sulfamate moiety binding to the active site $\mathrm{Zn}^{2+}$ cation. The steroid fragment of $\mathbf{7 5}$ and the coumarin fragment of $\mathbf{7 6}$ interact with the residues in the hydrophobic half of the CA II active site.

Figure 11. Steroidal sulfamate oestrone-3-O-sulphamate (EMATE) 75 and two coumarin based sulfamates, COUMATE-667 76 and STX-118 77. 


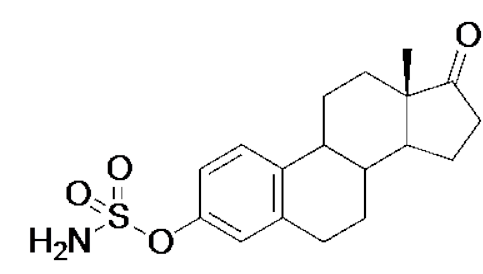

75

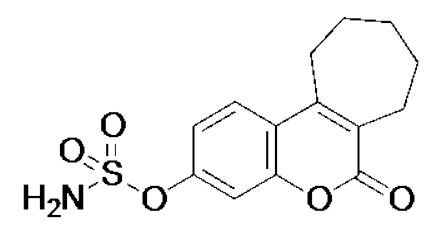

76

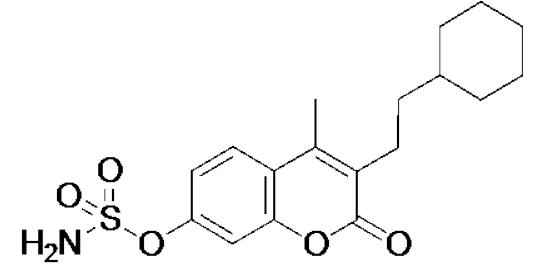

77

Table 5. Inhibition data of hCA Isozymes I, II, IX and XII and CLog P values for steroid- and coumarin-ZBG hybrid molecules 75-77. ( $\mathrm{nd}=$ not determined)

\begin{tabular}{ccccc}
\hline Compd & \multicolumn{4}{c}{$K_{\mathrm{i}}(\mathrm{nM})$} \\
\cline { 2 - 5 } & CA I & CA II & CA IX & CA X II \\
\hline $75(120)$ & 37 & 10 & 30 & nd \\
$76(121)$ & 3450 & 21 & 34 & 12 \\
$77(122)$ & nd & $\mathrm{IC}_{50}=59$ & nd & nd \\
\hline
\end{tabular}

\section{Conclusion}

Contemporary drug discovery is under increased pressure to identify more suitable small molecules as chemical starting points for drug development and finding novel compounds as starting points for optimisation is one of the major challenges in drug discovery research. NPs already provide a significant portion of FDA approved drugs and have emerged as an effective way to sample chemical diversity. The chemical diversity within NPs is vast and while the investigation of NP chemotypes for interaction with CAs is in its infancy, an encouraging start has been made. The NP compounds presented here (phenols, coumarins and polyamines) are suggestive of a tremendous opportunity that NPs provide for the discovery of novel chemotypes for selectively targeting either human or pathogen CAs. It will be imperative for future efforts to further evaluate the NP or NP-hybrid compounds in cell-based models of CA associated disease alongside classical control compounds for validation. The identification of unique CA binding for any NPs might offer possibilities for future rational drug discovery design and development. Thus the use of NPs in the search for new CA inhibitors has a strategic advantage since nature's unique chemical diversity has only been superficially explored in this particular field of research. We predict additional NP structures classes will be identified as binding to and perturbing CA function as further research is undertaken. 


\section{References}

1. Krishnamurthy, V. M., Kaufman, G. K., Urbach, A. R., Gitlin, I., Gudiksen, K. L., Weibel, D. B., and Whitesides, G. M. (2008) Carbonic Anhydrase as a Model for Biophysical and Physical-Organic Studies of Proteins and Protein-Ligand Binding. Chem. Rev. 108, 9461051.

2. (2012) Dictionary of Natural Products (DVD). Vol. version 18.2, Taylor \& Francis Group/CRC Press, London, UK

3. Thomas, S. O., Singleton, V. L., Lowery, J. A., Sharpe, R. W., Pruess, L. M., Porter, J. N., Mowat, J. H., and Bohonos, N. (1956) Nucleocidin, a new antibiotic with activity against Trypanosomes. Antibiotics annual, 716-721.

4. Rengaraju, S., Narayanan, S., Ganju, P. L., Amin, M. A., Iyengar, M. R. S., Sasaki, T., Miyadoh, S., Shomura, T., Sezaki, M., and Kojima, M. (1986) 5'-O-Sulfamoyladenosine (defluoronucleocidin) from a Streptomyces. Meiji Seika Kenkyu Nenpo, 49-55.

5. Takahashi, E., and Beppu, T. (1982) A new nucleosidic antibiotic AT-265. J. Antibiot. 35, 939-947.

6. Takahashi, E., and Osugi, K. (1988) Manufacture of 5'-sulfamoyl-2-bromoadenosine from Streptomyces. 6 pp, Kureha Chemical Industry Co., Ltd., Japan.

7. Iwata, M., Sasaki, T., Iwamatsu, H., Miyadoh, S., Tachibana, K., Matsumoto, K., Shomura, T., Sezaki, M., and Watanabe, T. (1987) A new herbicidal antibiotic, SF 2494 (5'-O-sulfamoyltubercidin) produced by Streptomyces mirabilis. Meiji Seika Kenkyu Nenpo, 17-22.

8. Iwata, M., Sasaki, T., Miyaji, S., Tachibana, K., Matsumoto, K., Shomura, T., and Sezaki, M. (1988) Antibiotic SF 2494, its manufacture with Streptomyces, and its use as herbicide. 8 pp, Meiji Seika Kaisha, Ltd., Japan.

9. Takahashi, A., Kurasawa, S., Ikeda, D., Okami, Y., and Takeuchi, T. (1989) Altemicidin, A New Acaricidal and Antitumour Substance. I. Taxonomy, fermentation, isolation and physicochemical and biological properties. J. Antibiot. 42, 1556-1561.

10. Kende, A. S., Liu, K., and Brands, K. M. J. (1995) Total Synthesis of (-)-Altemicidin: A Novel Ecploitation of the Potier-Polonovski Rearrangement. J. Am. Chem. Soc. 117, 10597-10598.

11. Jimenez, C., and Crews, P. (1991) Novel Marine Sponge Derived Amino Acids 13. Additional Psammaplin Derivatives from Psammaplysilla Purpurea. Tetrahedron 47, 2097-2102. 
12. Pina, I. C., Gautschi, J. T., Wang, G.-Y.-S., Sanders, M. L., Schmitz, F. J., Dennis France, D., Cornell-Kennon, S., Sambucetti, L. D., Remiszewski, S. W., Perez, L. B., Bair, K. W., and Crews, P. (2003) Psammaplins from the Sponge Pseudoceratina purpurea: Inhibition of Both Histone Deacetylase and DNA Methyltransferase. J. Org. Chem. 68, 3866-3873.

13. Kristinsson, K., Nebel, K., O'Sullivan, A. C., Pachlatko, J. P., and Yamaguchi, Y. (1995) Herbicidally active sulfamoyl nucleosides. Isolation and synthesis. ACS Symposium Series 584, 206-219.

14. Thomas, S. O., Singleton, V. L., Lowery, J. A., Sharpe, R. W., Pruess, L. M., Porter, J. N., Mowat, J. H., and Bohonos, N. (1957) Nucleocidin, a new antibiotic with activity against trypanosomes. Antibiotics Annual, 716-721.

15. Jenkins, I. D., Verheyden, J. P. H., and Moffatt, J. G. (1976) 4'-Substituted nucleosides. 2. Synthesis of the nucleoside antibiotic nucleocidin. J. Am. Chem. Soc. 98, 3346-3357.

16. Hewitt, R. I., Gumble, A. R., Taylor, L. H., and Wallace, W. S. (1957) Effectiveness of a new antibiotic, nucleocidin, in experimental infections with Trypanosoma equiperdum. Antibiotics Annual, 722-729.

17. Camp, D., Davis, R. A., Campitelli, M., Ebdon, J., and Quinn, R. J. (2012) Drug-like Properties: Guiding Principles for the Design of Natural Product Libraries. J. Nat. Prod. 75, 72-81.

18. Camp, D., Davis, R. A., Evans-Illidge, E. A., and Quinn, R. J. (2012) Guiding principles for natural product drug discovery. Future Med. Chem. 4, 1067-1084

19. Newman, D. J., and Cragg, G. M. (2007) Natural Products as Sources of New Drugs over the Last 25 Years. J. Nat. Prod. 70, 461-477.

20. Newman, D. J., and Cragg, G. M. (2009) Natural product scaffolds as leads to drugs. Future Med. Chem. 1, 1415-1427.

21. Lam, K. S. (2007) New aspects of natural products in drug discovery. Trends Microbiol. 15, 279-289.

22. Lachance, H., Wetzel, S., Kumar, K., and Waldmann, H. (2012) Charting, Navigating, and Populating Natural Product Chemical Space for Drug Discovery. J. Med. Chem. 55, 5989-6001.

23. Williams, D. A., and Lemcke, T. L., eds (2002) Foye's Principles of Medicinal Chemistry $5^{\text {th }}$ Edition, Lippincott Williams and Wilkins, Boston, pp 1-1114.

24. Butler, M. S., and Cooper, M. A. (2011) Antibiotics in the clinical pipeline in 2011. J. Antibiotics 64, 413-425. 
25. Mann, J. (2002) Natural products in cancer chemotherapy: past, present and future. Nat. Rev. Cancer 2, 143-148.

26. Newman, D. J., and Cragg, G. M. (2009) Natural product scaffolds as leads to drugs. Future Med. Chem. 1, 1415-1427.

27. Newman, D. J., and Cragg, G. M. (2012) Natural Products As Sources of New Drugs over the 30 Years from 1981 to 2010. J. Nat. Prod. 75, 311-335.

28. McArdle, B. M., and Quinn, R. J. (2007) Identification of Protein Fold Topology Shared between Different Folds Inhibited by Natural Products. ChemBioChem 8, 788-798.

29. Ertl, P., Roggo, S., and Schuffenhauer, A. (2008) Natural Product-likeness Score and Its Application for Prioritization of Compound Libraries. J. Chem. Inf. Model. 48, 68-74.

30. Grabowski, K., Baringhaus, K.-L., and Schneider, G. (2008) Scaffold dversity of natural products: inspiration for combinatorial library design. Nat. Prod. Rep. 25, 892-904.

31. Hert, J., Irwin, J. J., Laggner, C., Keiser, M. J., and Shoichet, B. K. (2009) Quantifying biogenic bias in screening libraries. Nat. Chem. Biol. 5, 479-483.

32. Rosen, J., Gottfries, J., Muresan, S., Backlund, A., and Oprea, T. I. (2009) Novel Chemical Space Exploration via Natural Products. J. Med. Chem. 52, 1953-1962.

33. Kellenberger, E., Hofmann, A., and Quinn, R. J. (2011) Similar interactions of natural products with biosynthetic enzymes and therapeutic targets could explain why nature produces such a large proportion of existing drugs. Nat. Prod. Rep. 28, 1483-1492.

34. Piggott, A. M., and Karuso, P. (2004) Quality, not quantity: the role of natural products and chemical proteomics in modern drug discovery. Comb. Chem. High. Throughput Screen. 7, 607-630.

35. Carlson, E. E. (2010) Natural Products as Chemical Probes. ACS Chem. Biol. 5, 639653.

36. Supuran, C. T. (2011) Carbonic anhydrase inhibition with natural products: novel chemotypes and inhibition mechanisms. Mol. Div. 15, 305-316.

37. Borges, F., Roleira, F., Milhazes, N., Santana, L., and Uriarte, E. (2005) Simple Coumarins and Analogues in Medicinal Chemistry: Occurrence, Synthesis and Biological Activity. Curr. Med. Chem. 12, 887-916.

38. Kontogiorgis, C., Detsi, A., and Hadjipavlou-Litina, D. (2012) Coumarin-based drugs: a patent review (2008 -- present). Expert Opin. Ther. Pat. 22, 437-454.

39. Vu, H., Pham, N. B., and Quinn, R. J. (2008) Direct screening of natural product extracts using mass spectrometry. J. Biomol. Screening 13, 265-275.

40. http://www.nature-bank.com.au 
41. Maresca, A., Temperini, C., Vu, H., Pham, N. B., Poulsen, S.-A., Scozzafava, A., Quinn, R. J., and Supuran, C. T. (2009) Non-zinc mediated inhibition of carbonic anhydrases: Coumarins are a new class of suicide inhibitors. J. Am. Chem. Soc. 131, 3057-3062.

42. Lopez, M., Vu, H., Wang, C. K., Wolf, M. G., Groenhof, G., Innocenti, A., Supuran, C. T., and Poulsen, S.-A. (2011) Promiscuity of Carbonic Anhydrase II. Unexpected Ester Hydrolysis of Carbohydrate-Based Sulfamate Inhibitors. J. Am. Chem. Soc. 133, 1845218462.

43. Krebs, J. F., Ippolito, J. A., Christianson, D. W., and Fierke, C. A. (1993) Structural and functional importance of a conserved hydrogen bond network in human carbonic anhydrase II. J. Biol. Chem. 268, 27458-27466.

44. Innocenti, A., Scozzafava, A., Parkkila, S., Puccetti, L., De Simone, G., and Supuran, C. T. (2008) Investigations of the esterase, phosphatase, and sulfatase activities of the cytosolic mammalian carbonic anhydrase isoforms I, II, and XIII with 4-nitrophenyl esters as substrates. Bioorg. Med. Chem. Lett. 18, 2267-2271.

45. Schultz, T. W., Rogers, K., and Aptula, A. O. (2009) Read-across to rank skin sensitization potential: subcategories for the Michael acceptor domain. Contact Dermatitis 60, 21-31.

46. Wolan, D. W., Zorn, J. A., Gray, D. C., and Wells, J. A. (2009) Small-Molecule Activators of a Proenzyme. Science 326, 853-858.

47. Aptula, A. O., Patlewicz, G., and Roberts, D. W. (2005) Skin Sensitization: Reaction Mechanistic Applicability Domains for Structure-Activity Relationships. Chem. Res. Toxicol. 18, 1420-1426.

48. Davis, R. A., Vullo, D., Maresca, A., Supuran, C. T., and Poulsen, S.-A. (2013) Natural product coumarins that inhibit human carbonic anhydrases. Bioorg. Med. Chem. 21, 1539-1543.

49. Sarker, S. D., Armstrong, J. A., Gray, A. I., and Waterman, P. G. (1994) Pyranocoumarins from Eriostemon apiculatus. Biochem. Syst. Ecol. 22, 641-644

50. Sarker, S. D., Armstrong, J. A., and Waterman, P. G. (1994) Angular pyranocoumarins from Eriostemon thryptomenoides. Biochem. Syst. Ecol. 22, 863-864.

51. Gray, A. I., Waigh, R. D., and Waterman, P. G. (1977) cis-Avicennol, a new pyranocoumarin from the root bark of Zanthoxylum elephantiasis. Phytochemistry 16, 1017-1018. 
52. Sultana, N., Sarker, S. D., Armstrong, J. A., Wilson, P. G., and Waterman, P. G. (2003) The coumarins of Philotheca sensu lato: distribution and systematic significance. Biochem. Syst. Ecol. 31, 681-691.

53. Kashman, Y., Gustafson, K. R., Fuller, R. W., Cardellina li, J. H., McMahon, J. B., Currens, M. J., Buckheit Jr, R. W., Hughes, S. H., Cragg, G. M., and Boyd, M. R. (1992) The calanolides, a novel HIV-inhibitory class of coumarin derivatives from the tropical rainforest tree, Calophyllum lanigerum. J. Med. Chem. 35, 2735-2743.

54. Dreyer, D. L., and Lee, A. (1972) Chemotaxonomy of the Rutaceae. VIII. Extractives of Geijera parviflora. Phytochemistry 11, 763-767.

55. Lahey, F. N., and MacLeod, J. K. (1967) Coumarins of Geijera pariflora. Aust. J. Chem. 20, 1943-1955.

56. Mujumdar, R. B., Rathi, S. S., and Rao, A. V. R. (1977) Heartwood constituents of Chloroxylon swietenia DC. Indian J. Chem., Sect. B 15B, 200-200.

57. Ahmad, J., Shamsuddin, K. M., and Zaman, A. (1984) A pyranocoumarin from Atalantia ceylanica. Phytochemistry 23, 2098-2099.

58. Spath, E., and Dobrovolny, E. (1938) Natural coumarins. XLII. Synthesis of fraxetin, fraxidin and isofraxidin. Ber. Dtsch. Chem. Ges. B 71B, 1831-1836.

59. Morikawa, T., Tao, J., Toguchida, I., Matsuda, H., and Yoshikawa, M. (2003) Structures of New Cyclic Diarylheptanoids and Inhibitors of Nitric Oxide Production from Japanese Folk Medicine Acer nikoense. J. Nat. Prod. 66, 86-91

60. Barbera, O., Alberto Marco, J., Sanz, J. F., and Sanchez-Parareda, J. (1986) 3Methoxyflavones and coumarins from Artemisia incanescans. Phytochemistry 25, 23572360.

61. Gonzalez, A. G., Diaz Chico, E., Lopez Dorta, H., Medina, J. M., and Rodriguez Luis, F. (1977) New sources of natural coumarins. XXXII. Chemical components of Ruta sp. Tene. 29662. An. Quim. 73, 1015-1018.

62. Zhang, W.-D., Kong, D.-Y., Li, H.-T., Gu, Z.-B., and Qin, L.-P. (1998) Chemical constituents of Erigeron breviscapus. Zhongguo Yiyao Gongye Zazhi 29, 498-500.

63. Lin, S., Wang, S., Liu, M., Gan, M., Li, S., Yang, Y., Wang, Y., He, W., and Shi, J. (2007) Glycosides from the Stem Bark of Fraxinus sieboldiana. J. Nat. Prod. 70, 817-823.

64. Wu, T. S., Tsang, Z. J., Wu, P. L., Lin, F. W., Li, C. Y., Teng, C. M., and Lee, K. H. (2001) New constituents and antiplatelet aggregation and anti-HIV principles of Artemisia capillaris. Bioorg. Med. Chem. 9, 77-83. 
65. Raj, K., Misra, S. C., Kapil, R. S., and Popli, S. P. (1976) Coumarins from Murraya paniculata. Phytochemistry 15, 1787-1787.

66. Ito, C., and Furukawa, H. (1987) Three new coumarins from the leaves of Murraya paniculata. Heterocycles 26, 2959-2962.

67. Nakamori, T., Taniguchi, M., Shibano, M., Wang, N.-H., and Baba, K. (2008) Chemical studies on the root of Heracleum candicans WALL. J. Nat. Med. 62, 403-412.

68. Bhatia, I. S., Bhatia, M. S., Sharma, R. S., and Bajaj, K. L. (1972) Polyphenolic constituents of the seeds and bark of Callistemon lanceolatus. Indian J. Chem. 10, 959959.

69. Rao, K. V. (1974) Toxic principles of Hippomane mancinella. Planta Medica 25, 166-171.

70. Lindquist, N., Fenical, W., Van Duyne, G. D., and Clardy, J. (1988) New alkaloids of the lamellarin class from the marine ascidian Didemnum chartaceum (Sluiter, 1909). J. Org. Chem. 53, 4570-4574.

71. Andersen, R. J., Faulkner, D. J., He, C. H., Van Duyne, G. D., and Clardy, J. (1985) Metabolites of the marine prosobranch mollusk Lamellaria sp. J. Am. Chem. Soc. 107, 5492-5495.

72. Davis, R. A., Carroll, A. R., Pierens, G. K., and Quinn, R. J. (1999) New Lamellarin Alkaloids from the Australian Ascidian, Didemnum chartaceum. J. Nat. Prod. 62, 419424.

73. Padmawinata, K. (1973) Isolation and identification of cancer delaying compounds from the leaves of Geijera salicifolia. Acta Pharm. 4, 1-9.

74. Jerris, P. J., and Smith III, A. B. (1981) Synthesis and configurational assignment of geiparvarin: a novel antitumor agent. J. Org. Chem. 46, 577-585.

75. Gunatilaka, L., Kingston, D., Wijeratne, K., Bandara, R., Hofmann, G., and Johnson, R. (1994) Biological Activity of Some Coumarins from Sri Lankan Rutaceae. J. Nat. Prod. 57, 518-520.

76. Nishimori, I., Vullo, D., Innocenti, A., Scozzafava, A., Mastrolorenzo, A., and Supuran, C. T. (2005) Carbonic anhydrase inhibitors. The mitochondrial isozyme VB as a new target for sulfonamide and sulfamate inhibitors. J. Med. Chem. 48, 7860-7866.

77. Casini, A., Antel, J., Abbate, F., Scozzafava, A., David, S., Waldeck, H., Schäfer, S., and Supuran, C. T. (2003) Carbonic anhydrase inhibitors: SAR and X-ray crystallographic study for the interaction of sugar sulfamates/sulfamides with isozymes I, II and IV. Bioorg. Med. Chem. Lett. 13, 841-845. 
78. De Simone, G., Di Fiore, A., Menchise, V., Pedone, C., Antel, J., Casini, A., Scozzafava, A., Wurl, M., and Supuran, C. T. (2005) Carbonic anhydrase inhibitors. Zonisamide is an effective inhibitor of the cytosolic isozyme II and mitochondrial isozyme V: solution and Xray crystallographic studies. Bioorg. Med. Chem. Lett. 15, 2315-2320.

79. Khalifah, R. G. (1971) The Carbon Dioxide Hydration Activity of Carbonic Anhydrase. J. Biol. Chem. 246, 2561-2573.

80. Carta, F., Maresca, A., Scozzafava, A., and Supuran, C. T. (2012) Novel coumarins and 2-thioxo-coumarins as inhibitors of the tumor-associated carbonic anhydrases IX and XII. Bioorg. Med. Chem. 20, 2266-2273.

81. Maresca, A., and Supuran, C. T. (2010) Coumarins incorporating hydroxy- and chloromoieties selectively inhibit the transmembrane, tumor-associated carbonic anhydrase isoforms IX and XII over the cytosolic ones I and II. Bioorg. Med. Chem. Lett. 20, 45114514.

82. Maresca, A., Temperini, C., Pochet, L., Masereel, B., Scozzafava, A., and Supuran, C. T. (2009) Deciphering the Mechanism of Carbonic Anhydrase Inhibition with Coumarins and Thiocoumarins. J. Med. Chem. 53, 335-344.

83. Nair, S. K., Ludwig, P. A., and Christianson, D. W. (1994) Two-Site Binding of Phenol in the Active Site of Human Carbonic Anhydrase II: Structural Implications for Substrate Association. J. Am. Chem. Soc. 116, 3659-3660.

84. Innocenti, A., Vullo, D., Scozzafava, A., and Supuran, C. T. (2008) Carbonic anhydrase inhibitors: Inhibition of mammalian isoforms I-XIV with a series of substituted phenols including paracetamol and salicylic acid. Bioorg. Med. Chem. 16, 7424-7428.

85. Innocenti, A., Sarikaya, S. B. O., Gulcin, I., and Supuran, C. T. (2010) Carbonic anhydrase inhibitors. Inhibition of mammalian isoforms I-XIV with a series of natural product polyphenols and phenolic acids. Bioorg. Med. Chem. 18, 2159-2164.

86. http://www.griffith.edu.au/science-aviation/queensland-compound-library

87. Davis, R. A., Hofmann, A., Osman, A., Hall, R. A., Mühlschlegel, F. A., Vullo, D., Innocenti, A., Supuran, C. T., and Poulsen, S. A. (2011) Natural Product-Based Phenols as Novel Probes for Mycobacterial and Fungal Carbonic Anhydrases. J. Med. Chem. 54, 1682-1692.

88. Davis, R. A., Innocenti, A., Poulsen, S.-A., and Supuran, C. T. (2010) Carbonic anhydrase inhibitors. Identification of selective inhibitors of the human mitochondrial isozymes VA and VB over the cytosolic isozymes I and II from a natural product-based phenolic library. Bioorg. Med. Chem. 18, 14-18. 
89. Davis, R. A. (2005) Isolation and Structure Elucidation of the New Fungal Metabolite (-)Xylariamide A. J. Nat. Prod. 68, 769-772.

90. Healy, P. C., Hocking, A., Tran-Dinh, N., Pitt, J. I., Shivas, R. G., Mitchell, J. K., Kotiw, M., and Davis, R. A. (2004) Xanthones from a microfungus of the genus Xylaria. Phytochemistry 65, 2373-2378.

91. Davis, R. A., Baron, P. S., Neve, J. E., and Cullinane, C. (2009) A microwave-assisted stereoselective synthesis of polyandrocarpamines A and B. Tetrahedron Lett. 50, 880882.

92. Davis, R. A., Aalbersberg, W., Meo, S., Moreira da Rocha, R., and Ireland, C. M. (2002) The isolation and synthesis of polyandrocarpamines A and B. Two new 2aminoimidazolone compounds from the Fijian ascidian, Polyandrocarpa sp. Tetrahedron 58, 3263-3269.

93. Davis, R. A., Carroll, A. R., Duffy, S., Avery, V. M., Guymer, G. P., Forster, P. I., and Quinn, R. J. (2007) Endiandrin A, a Potent Glucocorticoid Receptor Binder Isolated from the Australian Plant Endiandra anthropophagorum. J. Nat. Prod. 70, 1118-1121.

94. Davis, R. A., Barnes, E. C., Longden, J., Avery, V. M., and Healy, P. C. (2009) Isolation, structure elucidation and cytotoxic evaluation of endiandrin B from the Australian rainforest plant Endiandra anthropophagorum. Bioorg. Med. Chem. 17, 1387-1392.

95. Supuran, C. T. (2003) Carbonic anhydrase inhibitors in the treatment and prophylaxis of obesity. Expert Opin. Ther. Patents 13, 1545-1550

96. De Simone, G., Di Fiore, A., and Supuran, C. T. (2008) Are Carbonic Anhydrase Inhibitors Suitable for Obtaining Antiobesity Drugs? Curr. Pharm. Des. 14, 655-660.

97. Nishimori, I., Minakuchi, T., Kohsaki, T., Onishi, S., Takeuchi, H., Vullo, D., Scozzafava, A., and Supuran, C. T. (2007) Carbonic anhydrase inhibitors: The [beta]-carbonic anhydrase from Helicobacter pylori is a new target for sulfonamide and sulfamate inhibitors. Bioorg. Med. Chem. Lett. 17, 3585-3594.

98. Nishimori, I., Onishi, S., Takeuchi, H., and Supuran, C. T. (2008) The $\alpha$ and $\beta$ Classes Carbonic Anhydrases from Helicobacter pylori as Novel Drug Targets. Curr. Pharm. Des. 14, 622-630.

99. Isik, S., Kockar, F., Aydin, M., Arslan, O., Guler, O. O., Innocenti, A., Scozzafava, A., and Supuran, C. T. (2009) Carbonic anhydrase inhibitors: Inhibition of the $\beta$-class enzyme from the yeast Saccharomyces cerevisiae with sulfonamides and sulfamates. Bioorg. Med. Chem. 17, 1158-1163. 
100. Innocenti, A., Mühlschlegel, F. A., Hall, R. A., Steegborn, C., Scozzafava, A., and Supuran, C. T. (2008) Carbonic anhydrase inhibitors: Inhibition of the $\beta$-class enzymes from the fungal pathogens Candida albicans and Cryptococcus neoformans with simple anions. Bioorg. Med. Chem. Lett. 18, 5066-5070.

101. Innocenti, A., Hall, R. A., Schlicker, C., Scozzafava, A., Steegborn, C., Mühlschlegel, F. A., and Supuran, C. T. (2009) Carbonic anhydrase inhibitors. Inhibition and homology modeling studies of the fungal [beta]-carbonic anhydrase from Candida albicans with sulfonamides. Bioorg. Med. Chem. 17, 4503-4509.

102. Innocenti, A., Hall, R. A., Schlicker, C., Mühlschlegel, F. A., and Supuran, C. T. (2009) Carbonic anhydrase inhibitors. Inhibition of the $\beta$-class enzymes from the fungal pathogens Candida albicans and Cryptococcus neoformans with aliphatic and aromatic carboxylates. Bioorg. Med. Chem. 17, 2654-2657.

103. Joseph, P., Turtaut, F., Ouahrani-Bettache, S., Montero, J.-L., Nishimori, I., Minakuchi, T., Vullo, D., Scozzafava, A., Kolhler, S., Winum, J.-Y., and Supuran, C. T. (2010) Cloning, Characterization, and Inhibition Studies of a $\beta$-Carbonic Anhydrase from Brucella suis. J. Med. Chem. 53, 2277-2285.

104. Vullo, D., Nishimori, I., Scozzafava, A., Köhler, S., Winum, J.-Y., and Supuran, C. T. (2010) Inhibition studies of a $\beta$-carbonic anhydrase from Brucella suis with a series of water soluble glycosyl sulfanilamides. Bioorg. Med. Chem. Lett. 20, 2178-2182.

105. Wahle, K., Caruso, D., Ochoa, J., and Quiles, J. (2004) Olive oil and modulation of cell signaling in disease prevention. Lipids 39, 1223-1231.

106. Fu, G., Pang, H., and Wong, Y. (2008) Naturally Occurring Phenylethanoid Glycosides: Potential Leads for New Therapeutics. Curr. Med. Chem. 15, 2592-2613.

107. Davis, R. A., Watters, D., and Healy, P. C. (2005) The isolation and synthesis of 3chloro-4-hydroxyphenylacetamide produced by a plant-associated microfungus of the genus Xylaria. Tetrahedron Lett. 46, 919-921.

108. Casero, R. A., Jr, and Marton, L. J. (2007) Targeting polyamine metabolism and function in cancer and other hyperproliferative diseases. Nat. Rev. Drug Discovery 6, 373-390.

109. Fleidervish, I. A., Libman, L., Katz, E., and Gutnick, M. J. (2008) Endogenous polyamines regulate cortical neuronal excitability by blocking voltage-gated $\mathrm{Na}+$ channels. Proc. Natl. Acad. Sci. U. S. A. 105, 18994-18999.

110. Wallace, H. M., and Niiranen, K. (2007) Polyamine analogues - an update. Amino Acids 33, 261-265. 
111. Soda, K., Dobashi, Y., Kano, Y., Tsujinaka, S., and Konishi, F. (2009) Polyamine-rich food decreases age-associated pathology and mortality in aged mice. Exp. Gerontol. 44, 727-732.

112. Xu, M., Davis, R. A., Feng, Y., Sykes, M. L., Shelper, T., Avery, V. M., Camp, D., and Quinn, R. J. (2012) lanthelliformisamines A-C, Antibacterial Bromotyrosine-Derived Metabolites from the Marine Sponge Suberea ianthelliformis. J. Nat. Prod. 75, 10011005.

113. Yin, S., Davis, R. A., Shelper, T., Sykes, M. L., Avery, V. M., Elofsson, M., Sundin, C., and Quinn, R. J. (2011) Pseudoceramines A-D, new antibacterial bromotyrosine alkaloids from the marine sponge Pseudoceratina sp. Org. Biomol. Chem. 9, 6755-6760.

114. Buchanan, M. S. C., A. R.; Fechner, G. A.; Boyle, A.; Simpson, M. M.; Addepalli, R.; Avery, V. M.; Hooper, J. N. A.; Su, N.; Chen, H. W.; Quinn, R. J. (2007) Spermatinamine, the first natural product inhibitor of isoprenylcysteine carboxyl methyltransferase, a new cancer target. Bioorg. Med. Chem. Lett. 17, 6860-6863.

115. Carta, F., Temperini, C., Innocenti, A., Scozzafava, A., Kaila, K., and Supuran, C. T. (2010) Polyamines Inhibit Carbonic Anhydrases by Anchoring to the Zinc-Coordinated Water Molecule. J. Med. Chem. 53, 5511-5522.

116. Lopez, M., Paul, B., Hofmann, A., Morizzi, J., Wu, Q. K., Charman, S. A., Innocenti, A., Vullo, D., Supuran, C. T., and Poulsen, S.-A. (2009) S-Glycosyl Primary Sulfonamides A New Structural Class for Selective Inhibition of Cancer-Associated Carbonic Anhydrases. J. Med. Chem. 52, 6421-6432.

117. Rodriguez, O. M., Maresca, A., Tempera, C. A., Bravo, R. D., Colinas, P. A., and Supuran, C. T. (2011) N- $\beta$-Glycosyl sulfamides are selective inhibitors of the cancer associated carbonic anhydrase isoforms IX and XII. Bioorg. Med. Chem. Lett. 21, 44474450.

118. Lopez, M., Trajkovic, J., Bornaghi, L. F., Innocenti, A., Vullo, D., Supuran, C. T., and Poulsen, S.-A. (2011) Design, Synthesis, and Biological Evaluation of Novel Carbohydrate-Based Sulfamates as Carbonic Anhydrase Inhibitors. J. Med. Chem. 54, 1481-1489.

119. Woo, L. W. L., Purohit, A., Malini, B., Reed, M. J., and Potter, B. V. L. (2000) Potent active site-directed inhibition of steroid sulphatase by tricyclic coumarin-based sulphamates. Chemistry \& Biology 7, 773-791.

120. Winum, J.-Y., Vullo, D., Casini, A., Montero, J.-L., Scozzafava, A., and Supuran, C. T. (2003) Carbonic anhydrase inhibitors: Inhibition of cytosolic isozymes I and II and the 
membrane-bound, tumor associated isozyme IX with sulfamates also acting as steroid sulfatase inhibitors. J. Med. Chem. 46, 2197-2204.

121. Temperini, C., Innocente, A., Scozzafava, A., and Supuran, C. T. (2008) Carbonic anhydrase inhibitors. Interaction of the antitumor sulfamate EMD 486019 with twelve mammalian carbonic anhydrase isoforms: Kinetic and X-ray crystallographic studies. Bioorg. Med. Chem. Lett. 18, 4282-4286.

122. Ho, Y. T., Purohit, A., Vicker, V., Newman, S. P., Robinson, J. J., Leese, M. P., Ganeshapillai, D., Woo, L. W. L., Potter, B. V. L., and Reed, M. J. (2003) Inhibition of carbonic anhydrase II by steroidal and non-steroidal sulphamates. Biochem. Biophys. Res. Commun. 305, 909-914.

123. Lloyd, M. D., Pederick, R. L., Natesh, R., Woo, L. W., Purohits, A., Reed, M. J., Acharya, K. R., and Potter, B. V. L. (2005) Crystal structure of human carbonic anhydrase II at 1.95 Angstrom resolution in complex with 667-coumate, a novel anti-cancer agent. Biochem. J. 385, 715-720.

124. Abbate, F., Winum, J.-Y., Potter, B. V. L., Casini, A., Montero, J.-L., Scozzafava, A., and Supuran, C. T. (2004) Carbonic anhydrase inhibitors: X-ray crystallographic structure of the adduct of human isozyme II with EMATE, a dual inhibitor of carbonic anhydrases and steroid sulfatase. Bioorg. Med. Chem. Lett. 14, 231-234. 